\title{
Trunk Muscles Strength as a Risk Factor for Nonspecific Low Back Pain: A Pilot Study
}

\author{
Kang Hee Cho, $\mathrm{MD}^{1}$, Jae Won Beom, $\mathrm{MD}^{1}$, Tae Sung Lee, $\mathrm{MD}^{2}$, \\ Jun Ho Lim, $\mathrm{MD}^{1}$, Tae Heon Lee, BA ${ }^{1}$, Ji Hyun Yuk, $\mathrm{MS}^{1}$ \\ ${ }^{1}$ Department of Rehabilitation Medicine, Chungnam National University School of Medicine, Daejeon;
${ }^{2}$ Department of Rehabilitation Medicine, Yuseong Wellness Rehabilitation Hospital, Daejeon, Korea
}

Objective To investigate the effects of asymptomatic back muscle weakness and spinal deformity on low back pain (LBP).

Methods Sixty healthy subjects without LBP participated in this study. Radiography and an isokinetic/isometric dynamometer were used to respectively measure spinal scoliosis/lordosis and the strength of the trunk flexors/ extensors. After 2 years, 48 subjects visited the hospital again and LBP episodes, its severity and the Korean version of the Oswestry Disability Index were assessed. Differences between the group with LBP and the group without LBP were evaluated and the association with LBP incidence and severity was determined.

Results Sex, age, and trunk strength were significantly different in both group. Sex and age were significantly positive associated with LBP incidence. The isometric trunk flexor and extensor strength, maximum isokinetic trunk flexor and extensor strength were significantly and negatively associated with the LBP severity. The maximum isokinetic trunk extensor and maximum isometric trunk extensor strength was significantly negative associated with the LBP incidence.

Conclusion LBP incidence is associated with isometric and isokinetic trunk extensor weakness, whereas LBP severity is associated with age, sex, isokinetic trunk extensor and flexor weakness, isometric trunk extensor and flexor weakness.

Keywords Low back pain, Muscle weakness, Muscle strength dynamometer, Age, Sex

\footnotetext{
Received May 9, 2013; Accepted October 12, 2013

Corresponding author: Jun Ho Lim

Department of Rehabilitation Medicine, Chungnam National University Hospital, 282 Munhwa-ro, Jung-gu, Daejeon 301-721, Korea

Tel: +82-42-338-2460, Fax: +82-42-338-2461, E-mail: ljh2434@cnuh.co.kr

() This is an open-access article distributed under the terms of the Creative Commons Attribution Non-Commercial License (http://creativecommons. org/licenses/by-nc/3.0) which permits unrestricted noncommercial use, distribution, and reproduction in any medium, provided the original work is properly cited.

Copyright $\odot 2013$ by Korean Academy of Rehabilitation Medicine
}

\section{INTRODUCTION}

Low back pain (LBP) is common in the general population, affecting $60 \%$ individuals at some point in their lives, often causing appreciable disability [1]. Most episodes of back pain and associated symptoms resolve within several weeks [2]. However, LBP is a recurrent and chronic phenomenon, mostly associated with long-term disability and consequently is a significant socioeconomic burden [3]. These facts indicate that current interventions are being introduced too late and are not effective enough [4]. Early intervention before the first episode is 
the best method of prevention, but for this our understanding of the nature of LBP needs to improve.

The etiology of LBP and its natural course are important issues which remain to be poorly understood. An underlying specific pathology cannot be identified in most patients seeking primary care and approximately $90 \%$ of all low back problems are considered to have a non-specific origin [5]. It is essential to improve our understanding of its etiology and to analyze whether LBP has modifiable risk factors to decrease incidence and severity of LBP.

Although many studies on the etiopathogenesis of LBP exist, most of them have investigated the associations of exercise and muscle strength with chronic LBP $[6,7]$. Moreover, only few prospective studies have been conducted in individuals with asymptomatic spinal deformity and weakened trunk muscles.

The aim of this pilot study was to investigate the effects of asymptomatic back muscle weakness and spinal deformity on LBP incidence and the associations between asymptomatic trunk muscle weakness and LBP severity.

\section{MATERIALS AND METHODS}

We studied 60 healthy subjects without LBP (Fig. 1). The study population was recruited via poster notice at our hospital. All subjects provided written informed consent. Inclusion criteria were as follows: age 20-75 years; no previous history of spinal surgery and no history of lower extremity fracture (stress or traumatic). Exclusion criteria were as follows: subjects currently seeking medical care for LBP, pregnancy, poor general health, radicular pain, severe osteoporosis or severe psychological disturbances or psychiatric disease.

The baseline questionnaire included questions about age, gender, height and weight, and the body mass index (BMI) was calculated as well.

Standing anteroposterior and lateral views of the lumbar spine were obtained for the radiological evaluation. Then we measured the lumbar spine scoliosis angle using the Cobb angle method. We measured the lordosis angle between the upper border of $\mathrm{Ll}$ and the upper border of S1 on the lateral view radiographs. Scoliosis was considered to be present when the Cobb angle was greater than $10^{\circ}[8]$.

The strength test included two isometric tests and two isokinetic tests. We used the Biodex System 4 (Biodex Medical Systems, New York, NY, USA) dynamometer to measure the torque of the trunk flexors and extensors (Fig. 2). Subjects were advised to wear comfortable, loosefitting clothing on the day of testing. Both thighs and the back of subjects were fixed to the testing chair using straps. The axis of the dynamometer was located on the

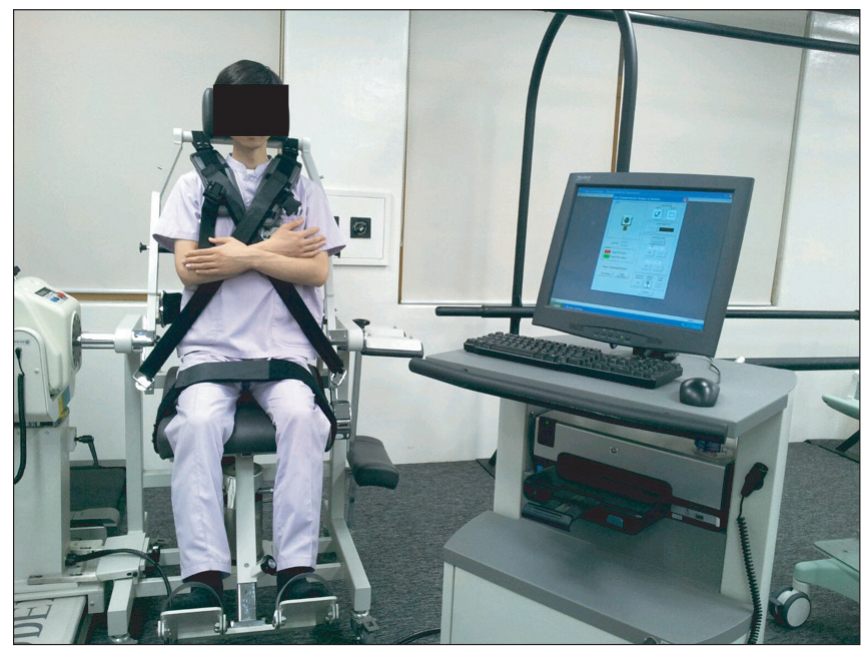

Fig. 2. Trunk strength test using Biodex System 4.

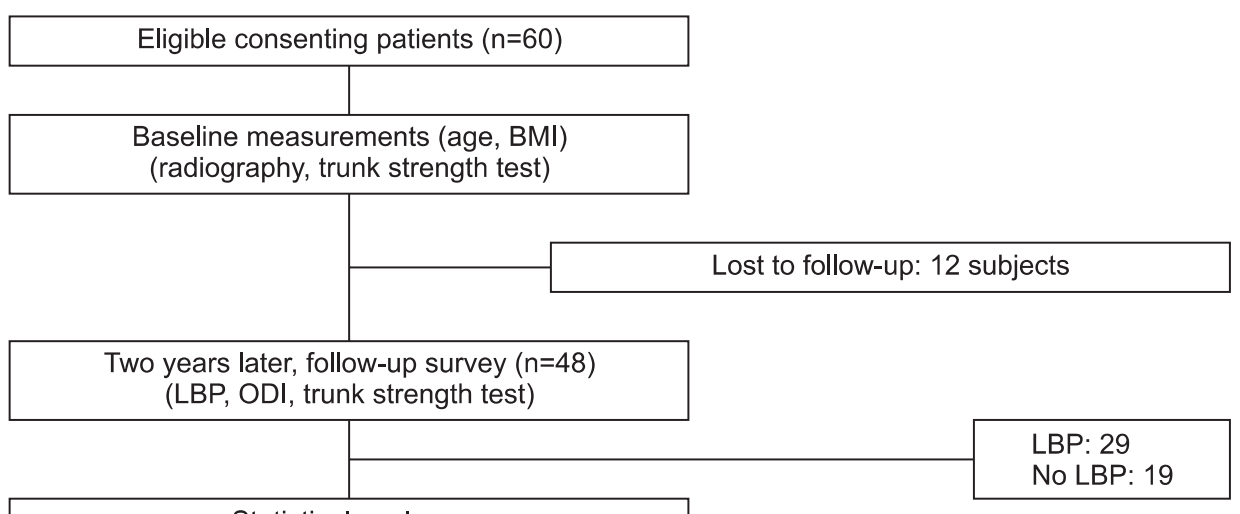

Statistical analyses
Fig. 1. Study design. BMI, body mass index; LBP, low back pain; ODI, Oswestry Disability Index. 
anterior superior iliac spine of the pelvis of the patient. Maximal isometric strength was measured of trunk flexors and extensors. The peak torque of three force measurements was recorded, for this the subjects held each contraction for 5 seconds. For the isokinetic strength test patients were instructed to perform flexion and extension of the back with maximum effort three times at an angular velocity of $120^{\circ} / \mathrm{s}$. The peak torque was expressed in Newton meter (N.m) and was normalized to the body weight $(\mathrm{N} \cdot \mathrm{m} / \mathrm{kg} \times 100 \%)$. Torque was proportional to power and the peak torque was the highest value within the range of motion.

Two years later, a follow-up survey was conducted. Forty-eight subjects visited the hospital again and answered questionnaires. These measures included the number of pain episodes, pain intensity with a numerical 0-10 rating scale and the Korean version of the Oswestry Low Back Pain Disability Questionnaire. The Korean version of the Oswestry Low Back Pain Disability Questionnaire was administered to every subject for measuring the Oswestry Disability Index (ODI). The questionnaire is a self-administered questionnaire divided into $10 \mathrm{sec}-$ tions designed to assess limitations of various activities of daily living [9].

Statistical analyses were performed using SPSS ver. 12.0 for Windows (SPSS Inc., Chicago, IL, USA). Associations were examined between sex, radiological abnormality and LBP incidence using chi-squared tests. Independent samples t-test was performed to analyze differences in age, BMI, isokinetic and isometric trunk torque between subjects with LBP and subjects without LBP. Associations were determined with correlation analyses between pain incidence and sex, age, BMI, isokinetic trunk torque, and isometric torque. A partial correlation analysis was developed in order to control the effect of sex and age. Variables with significant correlations with each were included in the multivariate model. The statistical significance level was fixed at 0.05 .

\section{RESULTS}

There were 20 males and 28 females and 12 subjects were lost to follow-up. Of those responding to the surveys, 29 of the 48 subjects reported at least one episode of LBP at the 2-year follow-up (mean \pm standard deviation, $1.6 \pm 0.7)$ and there was no trauma history. The mean age was $56.93 \pm 17.94$ years (range, $22-72$ years) in the group without LBP and $45.63 \pm 14.84$ years (range, 23-75 years) in the group with LBP; the ratio of men to women was 11:8 in the group without LBP and 6:23 in the group with LBP. The mean ODI was 5.0 (0-20). The mean Cobb angle of lumbar lordosis was $43.1^{\circ} \pm 11.1^{\circ}$ in the group without LBP and $48.1^{\circ} \pm 11.1^{\circ}$ in the group with LBP. The mean Cobb angle of lumbar scoliosis was $3.2^{\circ} \pm 3.0^{\circ}$ in the group without LBP and $3.9^{\circ} \pm 3.5^{\circ}$ in the group with LBP.

Sex and age were significantly different in both groups. Maximum isometric trunk flexor and extensor strength were significantly different. Also, maximum isokinetic trunk flexor and extensor strength were both significantly different. There were no significant differences of lumbar lordosis, scoliosis, and BMI between both groups (Tables 1, 2).

Sex and age were significantly and positively associated with LBP incidence $(r=0.38, p<0.01$ and $r=0.32, p<0.05$, respectively). After control of sex and age, maximum isometric trunk flexor and extensor strength, maximum isokinetic trunk flexor and extensor strength were significantly and negatively associated with LBP severity. The maximum isokinetic trunk extensor and maximum isometric trunk extensor strength were significantly and negatively associated with the incidence of LBP (Table 3).

\section{DISCUSSION}

In the prospective part of the study, the LBP incidence was found to be significantly and negatively associated

Table 1. Sex, scoliosis, and lordosis of subject

\begin{tabular}{lrccr}
\hline Variable & $\begin{array}{c}\text { Group } \\
\text { without LBP }\end{array}$ & $\begin{array}{c}\text { Group } \\
\text { with LBP }\end{array}$ & $\chi^{2}$ & p-value \\
\hline Sex & & & 6.947 & $0.008^{*}$ \\
Male & $11(57.9)$ & $6(20.7)$ & & \\
\hline Female & $8(42.1)$ & $23(79.3)$ & & \\
Scoliosis & & & 0.052 & 0.819 \\
$(-)$ & $18(94.7)$ & $27(93.1)$ & & \\
$(+)$ & $1(5.3)$ & $2(6.9)$ & & \\
\hline Lordosis & & & 0.202 & 0.653 \\
\hline$(-)$ & $13(68.4)$ & $18(62.1)$ & & \\
\hline$(+)$ & $6(31.6)$ & $11(37.9)$ & & \\
\hline
\end{tabular}

Values are presented as numbers (\%).

LBP, low back pain.

${ }^{*} \mathrm{p}<0.05$ by chi-squared test. 
Table 2. Characteristics of subjects

\begin{tabular}{|lcccc}
\hline \multicolumn{1}{c}{ Variable } & Group without LBP & Group with LBP & t & p-value \\
\hline Age $(\mathrm{yr})$ & $45.63 \pm 14.84$ & $56.93 \pm 17.94$ & -2.280 & $0.027^{*}$ \\
\hline $\mathrm{BMI}\left(\mathrm{kg} / \mathrm{m}^{2}\right)$ & $23.96 \pm 3.35$ & $24.24 \pm 3.13$ & -0.291 & 0.772 \\
\hline $\mathrm{IMF}^{\text {a) }}(\%)$ & $158.26 \pm 53.46$ & $102.35 \pm 58.77$ & 3.338 & $0.002^{*}$ \\
$\mathrm{IME}^{\mathrm{a})}(\%)$ & $275.00 \pm 68.19$ & $182.37 \pm 68.81$ & 4.577 & $0.000^{*}$ \\
\hline $\mathrm{IKF}^{\mathrm{a})}(\%)$ & $177.75 \pm 41.71$ & $118.81 \pm 61.42$ & 3.660 & $0.001^{*}$ \\
$\mathrm{IKE}^{\text {a) }}(\%)$ & $237.23 \pm 77.60$ & $135.73 \pm 81.82$ & 4.288 & $0.000^{*}$ \\
\hline Pain episode & $0.00 \pm 0.00$ & $1.55 \pm 0.74$ & -11.352 & $0.000^{*}$ \\
\hline Pain intensity (NRS) & $0.00 \pm 0.00$ & $3.10 \pm 2.16$ & -7.736 & $0.000^{*}$ \\
\hline ODI & $0.58 \pm 0.90$ & $7.86 \pm 5.31$ & -5.902 & $0.000^{*}$ \\
\hline
\end{tabular}

Values are presented as mean \pm standard deviation.

LBP, low back pain; BMI, body mass index; IMF, isometric flexor; IME, isometric extensor; IKR, isokinetic flexor; IKE, isokinetic extensor; NRS, numeric rating scale; ODI, Oswestry Disability Index.

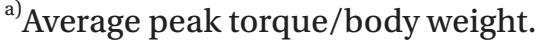

${ }^{*} \mathrm{p}<0.05$ by independent samples t-test.

Table 3. Partial correlation analysis

\begin{tabular}{cccccccccc}
\hline Control & Variable & & Pain & VAS & ODI & IMF & IME & IKE $^{\text {a) }}$ & IKF $^{\text {a) }}$ \\
\hline Sex, Age & Pain & $\mathrm{r}$ & 1 & - & - & - & - & - & - \\
& & $\mathrm{p}$ & - & - & - & - & - & - & - \\
& NRS & $\mathrm{r}$ & 0.603 & 1 & - & - & - & - & - \\
& & $\mathrm{p}$ & $0.000^{* * *}$ & - & - & - & - & - & - \\
& ODI & $\mathrm{r}$ & 0.609 & 0.694 & 1 & - & - & - & - \\
& & $\mathrm{p}$ & $0.000^{* * *}$ & 0 & - & - & - & - & - \\
& $\mathrm{IMF}^{\mathrm{a})}$ & $\mathrm{r}$ & -0.140 & -0.335 & -0.394 & 1 & - & - & - \\
& & $\mathrm{p}$ & 0.359 & $0.025^{*}$ & $0.007^{* *}$ & - & - & - & - \\
& $\mathrm{IME}^{\mathrm{a})}$ & $\mathrm{r}$ & -0.412 & -0.314 & -0.353 & 0.489 & 1 & - & - \\
& & $\mathrm{p}$ & $0.005^{* *}$ & $0.036^{*}$ & $0.017^{*}$ & $0.001^{* *}$ & - & - & - \\
& $\mathrm{IKE}^{\mathrm{a})}$ & $\mathrm{r}$ & -0.387 & -0.370 & -0.490 & 0.611 & 0.659 & 1 & - \\
& & $\mathrm{p}$ & $0.009^{* *}$ & $0.012^{*}$ & $0.001^{* *}$ & $0.000^{* * *}$ & $0.000^{* * *}$ & - & - \\
& $\mathrm{IKF}^{\mathrm{a})}$ & $\mathrm{r}$ & -0.241 & -0.378 & -0.396 & 0.771 & 0.308 & 0.670 & 1 \\
& & $\mathrm{p}$ & 0.110 & $0.010^{*}$ & $0.007^{* *}$ & $0.000^{* * *}$ & $0.040^{*}$ & $0.000^{* * *}$ & - \\
\hline
\end{tabular}

Pain, pain episode; VAS, visual analog scale; ODI, Oswestry Disability Index; IMF, isometric flexor; IME, isometric extensor; IKR, isokinetic flexor; IKE, isokinetic extensor; NRS, numeric rating scale (pain intensity).

${ }^{a}$ Average peak torque/body weight (\%).

${ }^{*} \mathrm{p}<0.05,{ }^{* *} \mathrm{p}<0.01,{ }^{* * *} \mathrm{p}<0.001$ by partial correlation analysis.

with age, sex, maximum isokinetic trunk extensor and maximum isometric trunk extensor strength, and the LBP severity was significantly and negatively associated with the maximum isometric trunk flexor and extensor strength, maximum isokinetic trunk flexor and extensor strength. BMI and lumbar spinal deformities had no association with LBP incidence and severity. The most interesting finding in this study was a strong association between paraspinal muscle strength and LBP incidence. Some strengths of this study were the recruitment of a cohort of subjects without a previous history of LBP and the measurement of the paraspinal muscle strength.

There are some longitudinal prospective studies about the development of LBP [10-13]. These studies were conducted for 10 to 24 months. Likewise, we collected the data over a period of 2 years. 
Several risk factors are associated with LBP. As it was shown here, the association between age and LBP was also reported in several other studies [14]. Modern living increases the tendency to have a more sedentary lifestyle that involves prolonged periods of sitting [15]. The disadvantages from prolonged sitting include increased intradiscal load and weakened posterior lumbar structures $[16,17]$. Previous research suggested that the prolonged sitting could be a risk factor for the development of LBP [18]. In addition, increasing age results in degenerative changes in the spine.

Persistent overweight has been associated with disc degeneration upon magnetic resonance imaging studies [19]. A study has reported that the reported prevalence of LBP was $22 \%$ among 5,724 obese adults aged over 60 years with a linear correlation between LBP and BMI [20]. However, the present study results show no significant association between BMI and LBP incidence. This may be probably because the subjects in the present study were not severely obese. Moreover, BMI does not provide any information about body composition and might be influenced by muscle mass and fat tissue.

The prevalence of back pain in scoliotic adults is no greater than that in the population at large [21], and the severity of LBP (intensity and duration) in scoliotic patients was no greater than that in control patients [22]. Similarly, lumbar lordosis and scoliosis were not associated with LBP incidence or severity in the present study.

The relationship between LBP incidence and the decrease of trunk muscle strength was widely studied, but there is no study about the different effect of isometric and isokinetic strength of trunk muscles. A decreased isometric strength of trunk extensors was associated with LBP occurrence [23].

The paraspinal muscles of the back support the spine and maintain its stability and they consist of the multifidus and the erector spinae. The multifidus is attached to the spine at every segment to provide stability. Moreover, the multifidus muscle sectional areas have been well correlated with isometric peak torque in all directions of movements [24]. The erector spinae mostly acts as a trunk extensor [25]. The results of this study suggest that the weakened isometric and isokinetic trunk extensors may be related to the LBP incidence and we assumed that the LBP incidence may be related to multifidus and erector spinae muscles.
The goal of prevention is to decrease the overall number of LBP episodes experienced by a certain population. Effective strategies for preventing LBP remain elusive. Back schools, lumbar supports and ergonomic interventions have limited evidence regarding prevention $[5,26]$. Previous study suggested that lumbar stabilization exercises that strengthen the multifidus muscles decrease LBP incidence and recurrence [27]. Exercise for LBP has focused on lumbar stabilization and core strengthening [28].

Some limitations should be considered. First, only small numbers of patients were included and they were recruited from one hospital only. Because of those limitations, the patients may not adequately represent the general population. Therefore further studies must be conducted to validate our results. Second, there is no structural evaluation of paraspinal muscles and we could not analyze the effect of muscle or fat tissue composition on LBP. Third, the LBP episodes were dependent on the memory of subjects and the time of occurrence and duration of LBP was not assessed. Last, this study did not address occupation, lifestyle and psychosocial factors. This is relevant because other studies have shown a significant association between tobacco consumption and LBP as well as intervertebral disc herniation [29]. Moreover, LBP were reported to be more frequent among married or divorced employees [11]. Thus, future studies should also consider social and occupational factors.

In conclusion, this study was a pilot study which evaluated the risk factor for nonspecific LBP. Our results indicate that an incidence of LBP is associated with isometric and isokinetic trunk extensor weakness and LBP severity is associated with isokinetic trunk extensor and flexor weakness and isometric trunk extensor and flexor weakness. Paraspinal muscle weakness in asymptomatic subjects can lead to an increase of LBP incidence and severity. Age and sex are not modifiable risk factors, but the strength of the trunk muscles is modifiable and can be improved by exercise of the paraspinal muscles. Thus, early strengthening exercises of the paraspinal muscles are necessary to decrease the LBP incidences and severity.

\section{CONFLICT OF INTEREST}

No potential conflict of interest relevant to this article was reported. 


\section{ACKNOWLEDGMENTS}

This study was supported by Chungnam National University Hospital Research Fund, 2011.

\section{REFERENCES}

1. Walsh K, Cruddas M, Coggon D. Low back pain in eight areas of Britain. J Epidemiol Community Health 1992;46:227-30.

2. Pengel LH, Herbert RD, Maher CG, Refshauge KM. Acute low back pain: systematic review of its prognosis. BMJ 2003;327:323.

3. Andersson GB. Epidemiological features of chronic low-back pain. Lancet 1999;354:581-5.

4. van den Hoogen HJ, Koes BW, van Eijk JT, Bouter LM, Deville W. On the course of low back pain in general practice: a one year follow up study. Ann Rheum Dis 1998;57:13-9.

5. Linton SJ, van Tulder MW. Preventive interventions for back and neck pain problems: what is the evidence? Spine (Phila Pa 1976) 2001;26:778-87.

6. Park YJ, Choi KS, Lee SG. Effect of lumbar extensor strengthening in chronic low back pain patients. J Korean Acad Rehabil Med 2000;24:295-300.

7. Kim KY. Clinico-radiologic findings of the whole spine in patients with chronic low back pain. J Korean Acad Rehabil Med 2000;24:137-45.

8. Vaz G, Roussouly P, Berthonnaud E, Dimnet J. Sagittal morphology and equilibrium of pelvis and spine. Eur Spine J 2002;11:80-7.

9. Jeon CH, Kim DJ, Kim SK, Kim DJ, Lee HM, Park HJ. Validation in the cross-cultural adaptation of the Korean version of the Oswestry Disability Index. J Korean Med Sci 2006;21:1092-7.

10. George SZ, Childs JD, Teyhen DS, Wu SS, Wright AC, Dugan JL, et al. Predictors of occurrence and severity of first time low back pain episodes: findings from a military inception cohort. PLoS One 2012;7:e30597.

11. Bejia I, Younes M, Jamila HB, Khalfallah T, Ben Salem $\mathrm{K}$, Touzi M, et al. Prevalence and factors associated to low back pain among hospital staff. Joint Bone Spine 2005;72:254-9.

12. Evans K, Refshauge KM, Adams R, Aliprandi L. Predictors of low back pain in young elite golfers: a preliminary study. Phys Ther Sport 2005;6:122-30.
13. Burdorf A, Jansen JP. Predicting the long term course of low back pain and its consequences for sickness absence and associated work disability. Occup Environ Med 2006;63:522-9.

14. Chon J, Kim SW, Kim SS, Kim YG, Choi HJ, Ahn KH, et al. Risk factors of low back pain in a general population. J Korean Acad Rehabil Med 2000;24:981-7.

15. Egger GJ, Vogels N, Westerterp KR. Estimating historical changes in physical activity levels. Med J Aust 2001;175:635-6.

16. Nachemson A. The load on lumbar disks in different positions of the body. Clin Orthop Relat Res 1966;45:107-22.

17. Hedman TP, Fernie GR. Mechanical response of the lumbar spine to seated postural loads. Spine (Phila $\mathrm{Pa}$ 1976) 1997;22:734-43.

18. Pope MH, Goh KL, Magnusson ML. Spine ergonomics. Annu Rev Biomed Eng 2002;4:49-68.

19. Liuke M, Solovieva S, Lamminen A, Luoma K, LeinoArjas P, Luukkonen R, et al. Disc degeneration of the lumbar spine in relation to overweight. Int J Obes (Lond) 2005;29:903-8.

20. Leboeuf-Yde C. Body weight and low back pain: a systematic literature review of 56 journal articles reporting on 65 epidemiologic studies. Spine (Phila Pa 1976) 2000;25:226-37.

21. Jackson RP, Simmons EH, Stripinis D. Incidence and severity of back pain in adult idiopathic scoliosis. Spine (Phila Pa 1976) 1983;8:749-56.

22. Gremeaux V, Casillas JM, Fabbro-Peray P, Pelissier J, Herisson C, Perennou D. Analysis of low back pain in adults with scoliosis. Spine (Phila Pa 1976) 2008;33:402-5.

23. Alaranta H, Luoto S, Heliovaara M, Hurri H. Static back endurance and the risk of low-back pain. Clin Biomech (Bristol, Avon) 1995;10:323-4.

24. Han TR, Kim JH, Chung SG, Kwon BS, Lee KW. Correlation of ultrasonographic measure of lumbar multifidus muscles with isometric torque of low back. J Korean Acad Rehabil Med 1999;23:809-14.

25. Brukner P, Khan K. Clinical sports medicine. 3rd rev. ed. Sydney: McGraw-Hill; 2010.

26. Bigos SJ, Holland J, Holland C, Webster JS, Battie M, Malmgren JA. High-quality controlled trials on preventing episodes of back problems: systematic literature review in working-age adults. Spine J 2009;9:147- 
68.

27. Hides JA, Jull GA, Richardson CA. Long-term effects of specific stabilizing exercises for first-episode low back pain. Spine (Phila Pa 1976) 2001;26:E243-8.

28. Barr KP, Griggs M, Cadby T. Lumbar stabilization: a review of core concepts and current literature, part 2.
Am J Phys Med Rehabil 2007;86:72-80.

29. Hestbaek L, Leboeuf-Yde C, Kyvik KO. Are lifestylefactors in adolescence predictors for adult low back pain? A cross-sectional and prospective study of young twins. BMC Musculoskelet Disord 2006;7:27. 